\title{
ON THE GENERALIZED HYERS-ULAM STABILITY OF QUARTIC MAPPINGS IN NON-ARCHIMEDEAN BANACH SPACES
}

\author{
H. Azadi Kenary, H. Keshavarz, C. Park and D. Y. Shin
}

Abstract. Let $X, Y$ are linear space. In this paper, we prove the generalized Hyers-Ulam stability of the following quartic equation

$$
\begin{aligned}
& \sum_{k=2}^{n}\left(\sum_{i_{1}=2}^{k} \sum_{i_{2}=i_{1}+1}^{k+1} \ldots \sum_{i_{n-k+1}=i_{n-k}+1}^{n}\right) f\left(\sum_{i=1, i \neq i_{1}, \ldots, i_{n-k+1}}^{n} x_{i}-\sum_{r=1}^{n-k+1} x_{i_{r}}\right)+f\left(\sum_{i=1}^{n} x_{i}\right) \\
& =2^{n-2} \sum_{1 \leqslant i<j \leqslant n}\left(f\left(x_{i}+x_{j}\right)+f\left(x_{i}-x_{j}\right)\right)-2^{n-5}(n-2) \sum_{i=1}^{n} f\left(2 x_{i}\right)
\end{aligned}
$$

$(n \in \mathbb{N}, n \geqslant 3)$ in non-Archimedean Banach spaces

Mathematics subject classification (2010): 39B82, 39B52.

Keywords and phrases: Stability, quartic mapping, non-Archimedean normed space.

\section{REFERENCES}

[1] H. AZAdi Kenary, Stability of a Pexiderial functional equation in random normed spaces, Rend. Circ. Mat. Palermo (2011) 60:59-68, DOI 10.1007/s12215-011-0027-5.

[2] H. AZADI KenARY, Random approximation of an additive functional equation of $m$-appollonius type, Acta Mathematica Scientia, Volume 32, Issue 5, 2012, Pages 1813-1825.

[3] H. Azadi Kenary, Approximation of a Cauchy-Jensen Additive Functional Equation in NonArchimedean Normed Spaces, Acta Mathematica Scientia, Volume 32, Issue 6, 2012, Pages 22472258.

[4] H. Azadi Kenary And Y. J. Cho, Stability of mixed additive-quadratic Jensen type functional equation in various spaces, Computers and Mathematics with Applications, Volume 61, Issue 9, 2011, Pages 2704-2724.

[5] H. AZadi Kenary, H. Rezaei, M. SharifZadeh, D. Y. Shin and J. R. Lee, Non-Archimedean Hyers-Ulam-Rassias stability of $m$-variable functional equation, Advances in Difference Equations 2012, 2012:111.

[6] H. Azadi Kenary, Th. M. Rassias, C. Park, Hyers-Ulam-Rassias stability of the additivequadratic mappings in non-Archimedean spaces, Journal of Inequalities and Applications 2012, 2012:174.

[7] L. CĂDARIU, AND V. RADU, Fixed points and the stability of Jensen's functional equation, J Inequal Pure Appl Math. 4, Article ID 4 (2003).

[8] D. DESES, On the representation of non-Archimedean objects, Topology Appl. 153 (2005), 774-785.

[9] M. Eshaghi Gordu AND M. B. SAVAdKouni, Stability of a mixed type cubic-quartic functional equation in non-Archimedean spaces, Appl. Math. Lett., 23 (2010), 1198-1202.

[10] K. Hensel, Ubereine news Begrundung der Theorie der algebraischen Zahlen, Jahresber. Deutsch. Math. Verein 6 (1897), 83-88.

[11] D. H. Hyers, On the stability of the linear functional equation, Proc. Nat. Acad. Sci. U.S.A. 27 (1941), 222-224.

[12] D. Mineţ AND V. RADU, On the stability of the additive Cauchy functional equation in random normed spaces, J. Math. Anal. Appl. 343 (2008), 567-572. 
[13] P. J. Nyikos, On some non-Archimedean spaces of Alexandrof and Urysohn, Topology Appl. 91 (1999), 1-23.

[14] C. PARK, Fixed points and Hyers-Ulam-Rassias stability of Cauchy-Jensen functional equations in Banach algebras, Fixed Point Theory and Applications 2007, Art. ID 50175 (2007).

[15] V. RADU, The fixed point alternative and the stability of functional equations, Fixed Point Theory 4 (2003), 91-96.

[16] Th. M. Rassias, On the stability of the linear mapping in Banach spaces, Proc. Amer. Math. Soc. 72 (1978), 297-300.

[17] K. Ravi, J. M. Rassias, M. Arunkumar, And R. Kodandan, Stability of a generalized mixed type additive, quadratic, cubic and quartic functional equation, Journal of Inequalities in Pure and Applied Mathematics, vol. 10, no. 4, article 114, pp. 1-29, 2009.

[18] S. M. Ulam, Problems in Modern Mathematics, Wiley, New York, 1960. 